\title{
Use of benzodiazepines and related drugs in Manitoba: a population-based study
}

\author{
Silvia Alessi-Severini PhD, James M. Bolton MD, Murray W. Enns MD, Matthew Dahl BSc, \\ David M. Collins PhD, Dan Chateau PhD, Jitender Sareen MD
}

Abstract

Background: Despite their favourable toxicology profile, benzodiazepines and the related Z-drugs (zopiclone, zolpidem and zaleplon) have been associated with physiological tolerance, dependence and addiction. Evidence of harm (e.g., falls, motor vehicle collisions and cognitive disturbances) has been reported in older populations. The aim of this study was to determine the relation between users' characteristics and the use of benzodiazepines and Z-drugs in Manitoba over a 16-year period.

Methods: This time-series analysis was based on prescription data from Apr. 1, 1996, to Mar. 31, 2012, obtained from the Drug Product Information Network database of Manitoba. We obtained sociodemographic information on benzodiazepine and Z-drug users from the Population Registry and determined changes in utilization rates over time using generalized estimating equations.

Results: Overall, the prevalence of benzodiazepine use remained stable at about 61.0 per 1000 population between $1996 / 97$ and 2011/12; however, the prevalence of Z-drug use increased steadily from 10.9 to 37.0 per 1000 over the same period. In older people ( $\geq 65 \mathrm{yr}$ ), the incidence of benzodiazepine use decreased from 55.5 to 30.3 users per 1000, whereas the incidence of Z-drug use increased from 7.3 to 20.3 users per 1000 over the study period. Among those 18-64 years of age, the incidence of benzodiazepine use decreased from 30.1 to 27.6 users per 1000, but the increase in incidence of Z-drug use was more than 2-fold. The youngest population $(\leq 17 \mathrm{yr}$ ) showed the lowest rates of use of these drugs. The highest rates of use were observed among older women and the low-income population.

Interpretation: Over the study period, benzodiazepines have been prescribed less frequently to older patients in Manitoba; however, zopiclone prescribing has continued to increase for all age groups. The reasons for this increase remain to be determined.

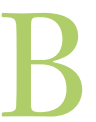

enzodiazepines have been used for decades as effective agents for the treatment of seizure and anxiety disorders and for the short-term control of insomnia. Although their toxicology profile is favourable compared with other hypnotic drugs and sedatives, such as barbiturates, their long-term use has been associated with physiological tolerance, dependence and addiction. ${ }^{1-3}$ Harm, supported by various levels of evidence, has been widely reported and includes higher risk of falls and fractures, ${ }^{4-6}$ motor vehicle collisions $^{7}$ and cognitive disturbances particularly among older people. ${ }^{8}$ Newer non-benzodiazepine agents (i.e., zopiclone, zolpidem and zaleplon), commonly called Z-drugs, are indicated for sleep disorders. Although it has been suggested that Z-drugs have a lower potential for abuse and dependence, ${ }^{9}$ their use can also be problematic because of their effects on human performance and driving. ${ }^{10,11}$

Because of these potential adverse effects, clinical practice guidelines have advised against the use of benzodiazepines and Z-drugs for longer than 4 weeks, and health agencies worldwide have undertaken anti-benzodiazepine and anti-Z-drug campaigns, not without controversy. ${ }^{12-18}$ However, the dearth of published research studies on this subject suggests that such recommendations have not had a significant impact on the use of benzodiazepines and Z-drugs in various countries. ${ }^{19-22}$ The only population-based study conducted in Canada was based on data from British Columbia and examined a period of 10 years between 1996 and 2006. ${ }^{20}$ As there are long delays between the reporting of scientific knowledge and changes in clinical practice, changes in prescribing patterns may have occurred over the last 7 years. Thus, in this study, we describe the prescribing patterns for benzodiazepines and Z-drugs for the entire population of a Canadian province over 16 years by user characteristics.

Competing interests: None declared.

This article has been peer reviewed.

Correspondence to: Silvia Alessi-Severini, silvia.alessi-severini@ umanitoba.ca

CMAJ Open 2014.DOI:10.9778/cmajo.20130076 


\section{Methods}

\section{Study population}

All Manitoba residents registered with the provincial health care system who were prescribed a benzodiazepine or a Z-drug between 1996/97 and 2011/12 were included. No age restrictions were applied, but patients were stratified by sex and age $(0-17,18-64$ and $\geq 65 \mathrm{yr})$. Location of residence (urban v. rural) and socioeconomic status were also assessed. According to validated definitions, ${ }^{23}$ incident (new) users were defined as people who had not received a prescription for any of the medications of interest in the year before receiving their first prescription, while prevalent users for each fiscal year were defined as people who had received at least 1 prescription for a medication of interest that year.

\section{Data sources}

Administrative data on the use of benzodiazepines and Z-drugs between Apr. 1, 1996, and Mar. 31, 2012, were obtained from the Manitoba Population Health Research Data Repository, housed at the Manitoba Centre for Health Policy. Patient records in the repository are de-identified using an encrypted personal health information number as a quasi-identifier to protect privacy. Databases used in this study include the Population Registry, which contains demographic information for all residents of Manitoba, and the Drug Product Information Network, which contains prescription data. The latter includes prescriptions dispensed in Manitoba regardless of the type of insurance coverage (government-sponsored, private or out-ofpocket) and, thus, provides a comprehensive description of non-hospital drug use. Medications administered in hospital and physician samples are not included. Prescriptions dispensed to First Nations patients served by northern nursing stations may by underestimated because of incomplete data entry during the early use of the system. However, the database has been determined to be over $90 \%$ accurate in terms of prescriptions dispensed in the community. ${ }^{24}$

\section{Measures}

All benzodiazepines available on the Canadian market during the study were included. Drug identification numbers were retrieved from Health Canada's drug product database using the codes of the Anatomical Therapeutic Chemical classification system (Box 1). The Z-drugs included in the study were zopiclone and zaleplon; zolpidem was not included as it did not become available on the Canadian market until the end of 2011.

Population sizes, ranging from 1144087 in 1996/97 to 1261373 in 2011/12, for use in calculating overall prevalence and incidence, were obtained from the Population Registry as Dec. 31 snapshots for each year. The 3 age groups ranged from 296658 people in 1996/97 to 291782 in 2011/12 for those $0-17$ years of age, from 692539 to 793093 for those 18-64 years of age and from 154890 to 176498 for those 65 years of age and older.

Region of residence (rural v. urban) was determined by postal codes registered with Manitoba Health. Socioeconomic status was based on median neighbourhood income quintiles provided by Statistics Canada for the dissemination area in which patients resided: low income included the lowest and second-lowest quintiles, high income included the 3 highest quintiles. People to whom a neighbourhood income could not be assigned (i.e., residents of personal care homes, psychiatric facilities and prisons and wards of the public trustee and Child and Family Services) were grouped into a "not found" category.

Prescriber specialties were derived from the de-identified physician identification number reported on the prescription and classified as general practitioner, psychiatrist or other medical specialty.

\section{Statistical analyses}

Separate analyses were conducted to evaluate prevalent and incident use of benzodiazepines and Z-drugs. Generalized estimating equations, which addressed the correlated structure of the data, ${ }^{25,26}$ were used to analyze incident and prevalent use over time as number of users per 1000 population and to determine the influence of sociodemographic characteristics (age, sex, region of residence and socioeconomic status) on prescribing over the entire study period. For analyses, we used SAS statistical software (v 9.2, SAS Institute, Cary, NC).

\section{Ethics approval}

The study was approved by the Health Research Ethics Board of the Faculty of Medicine, University of Manitoba (H2009024). The study was conducted in full compliance with the Personal Health Information Act of Manitoba, and privacy/ confidentiality consent was obtained from the Health Information Privacy Committee of the Government of Manitoba (\#2008/2009-48).

\section{Results}

\section{Incidence of benzodiazepine and Z-drug use}

Lorazepam was the benzodiazepine most often prescribed during the study period, with the number of new users remaining fairly stable: from 14.0 per 1000 population in $1996 / 97$ to 15.0 per 1000 in 20011/12 (Figure 1). The incidence of use of other benzodiazepines was lower. Clonazepam was the second-most prescribed benzodiazepine in recent years, with incidence of its use increasing from 1.3 per 1000 in 1996/97 to 2.7 per 1000 in 2011/12. The incidence of diazepam use decreased by more than half between 1996/97 and 2011/12 (from 3.0 to 1.3 per 1000). The incidence of alprazolam and temazepam prescribing also decreased over the same period: from 2.4 to 1.1 per 1000 and from 2.4 to 1.7 per 1000 , respectively.

The incidence of benzodiazepine use decreased significantly among older adults ( $\geq 65 \mathrm{yr}$ ) from 55.5 per 1000 population in $1996 / 97$ to 30.3 per 1000 in 2011/2012, but use of Z-drugs by this population increased consistently from 7.3 to 20.3 per 1000 over the same period (Figure 2). During the study period, the number of new users of zopiclone in this age group increased by 37691 . 
The adult population between 18 and 64 years of age showed a slight decrease in incidence of benzodiazepine use, from 30.1 to 27.6 per 1000 population, but the increase in incidence of Z-drug use was more than 2-fold: from 4.7 per 1000 in 1996/97 to 11.1 per 1000 in 2011/12 (Figure 2). The number of new users of zopiclone and zaleplon in the 18-64 age group increased by 99361 over the study period.

The youngest segment of the population $(0-17 \mathrm{yr})$ showed the lowest overall incidence of benzodiazepine and Z-drug use, with only 1589 new users over the study period; however, among this population, the incidence of use of both classes of drugs increased significantly: from 2.20 per 1000 in $1996 / 97$ to 3.95 per 1000 in 2011/12 for benzodiazepines; and from 0.19 to 0.39 per 1000 for $Z$-drugs over the same time period (Figure 2).

\section{Prevalence of benzodiazepine and Z-drug use}

Over the study period, the prevalence of lorazepam use increased from 33.4 to 41.5 per 1000 population (Figure 3). For clonazepam, prevalence increased from 5.6 per 1000 population in $1996 / 97$ to 15.8 per 1000 in 2011/12 The prevalence of temazepam use also increased from 8.1 per 1000 in $1996 / 97$ to 12.0 per 1000 in 2011/12. In contrast, the prevalence of diazepam use showed a significant decrease from 10.5 to 5.8 per 1000 over the study period. Alprazolam prevalence remained stable at approximately 7.0 per 1000 .
Stratification by age group (Figure 4) showed that, since 2005/06, the prevalence of both benzodiazepine and Z-drug use was highest among the oldest population group: benzodiazepine prevalence among this group decreased from 174.7 to 120.6 per 1000 over the study period, but $Z$-drug use increased steadily from 25.2 to 93.9 per 1000 in the same period.

\begin{tabular}{|ll|}
\hline $\begin{array}{l}\text { Box 1: Benzodiazepines and related drugs } \\
\text { available in Manitoba over the study period } \\
\text { (1996-2012), listed by generic name and } \\
\text { Anatomical Therapeutic Chemical code }\end{array}$ \\
\hline Alprazolam & N05BA12 \\
\hline Bromazepam & N05BA08 \\
\hline Chlordiazepoxide & N05BA02 \\
\hline Clobazam & N05BA09 \\
\hline Clonazepam & N03AE01 \\
\hline Diazepam & N05BA01 \\
\hline Flurazepam & N05BA17 \\
\hline Lorazepam & N05BA06 \\
\hline Oxazepam & N05BA04 \\
\hline Temazepam & N05CD07 \\
\hline Triazolam & N05CD05 \\
\hline Zopiclone & N05CF01 \\
\hline Zaleplon & N05CF03 \\
\hline
\end{tabular}

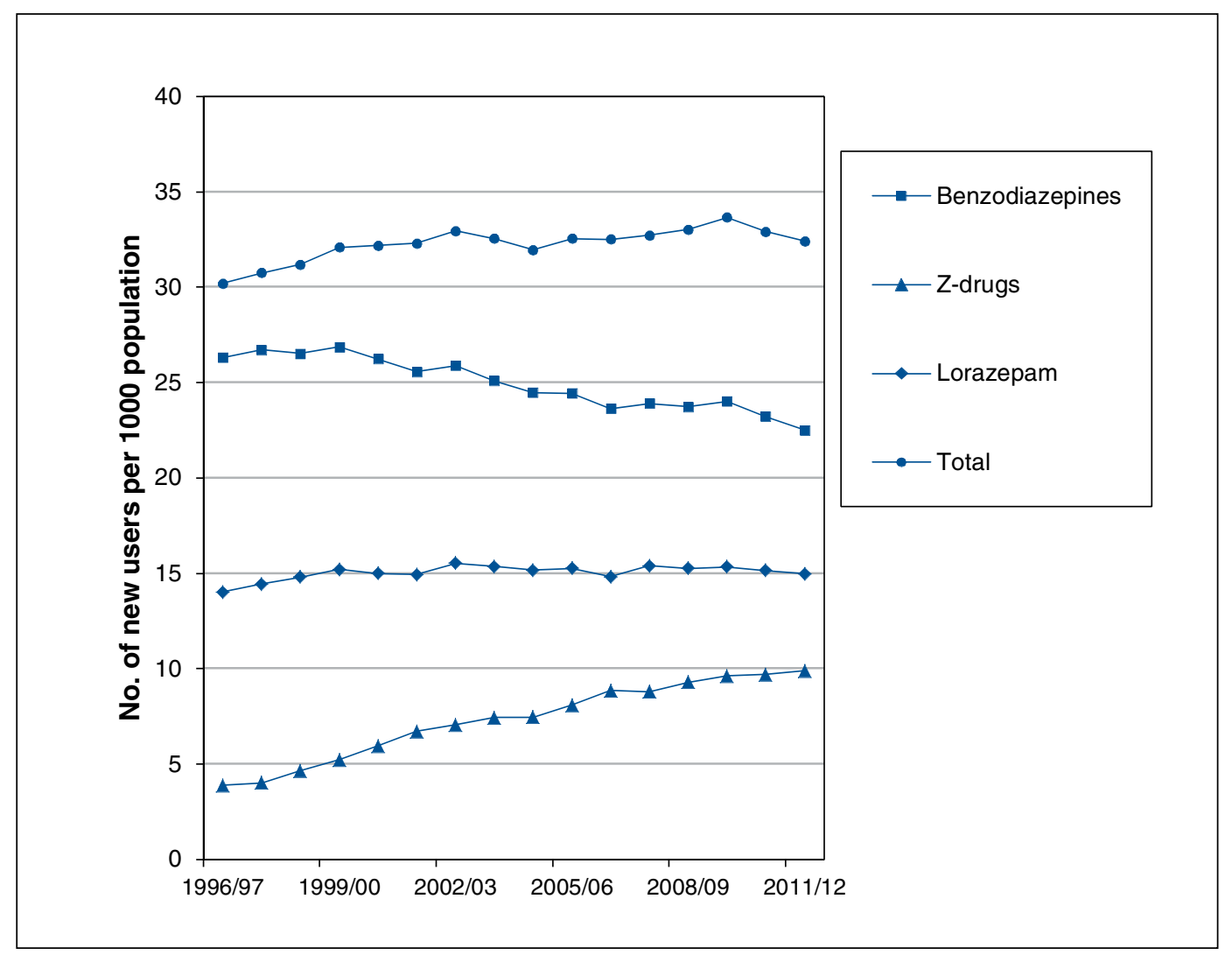

Figure 1: Incidence of benzodiazepine and Z-drug (zopiclone and zaleplon) use in Manitoba, 1996-2012. 
In the other 2 age groups, prevalence of benzodiazepine use increased from 62.1 to 67.9 per 1000 among the 18-64 year olds and from 2.7 to 5.6 per 1000 among the $0-17$ year olds. For the Z-drugs, prevalence increased from 12.2 to 37.8 per 1000 and from 0.29 to 0.62 per 1000 among the $18-64$ and the $0-17$ age groups, respectively (Figure 4).

\section{Effects of sex, place of residence and socioeconomic status}

Stratification by sex showed that the incidence of both benzodiazepine and Z-drug use was higher among females than males over the study period. The incidence of benzodiazepine use decreased slightly among females from 33.2 to 28.3 per 1000 , compared with a decrease from 19.2 to 17.3 per 1000 among males. The incidence of Z-drug use among females increased from 4.6 to 11.8 per 1000; among males, the increase was from 3.2 to 8.0 per 1000 . These changes were significant (Table 1 ).
Region of residence did not have a significant effect on incidence of use. High socioeconomic status was associated with a higher incidence of Z-drug use.

The prevalence of benzodiazepine use among males was 42.7 per 1000 in 1996/97 and 44.4 per 1000 in 2011/12; among females, the prevalence was 80.1 per 1000 in 1996/97 and 77.0 in 2011/12. The prevalence of Z-drug use increased significantly from 13.4 to 47.4 per 1000 among females and from 8.3 to 26.4 per 1000 among males (Table 2).

Urban place of residence was associated with a higher prevalence of benzodiazepine use. High socioeconomic status was associated with a higher prevalence of Z-drug use, but a lower prevalence of benzodiazepine use (Table 2).

\section{Prescriptions}

In 2011/12, more than 1 million prescriptions for benzodiazepines and Z-drugs were dispensed in Manitoba. In 1996/97, a

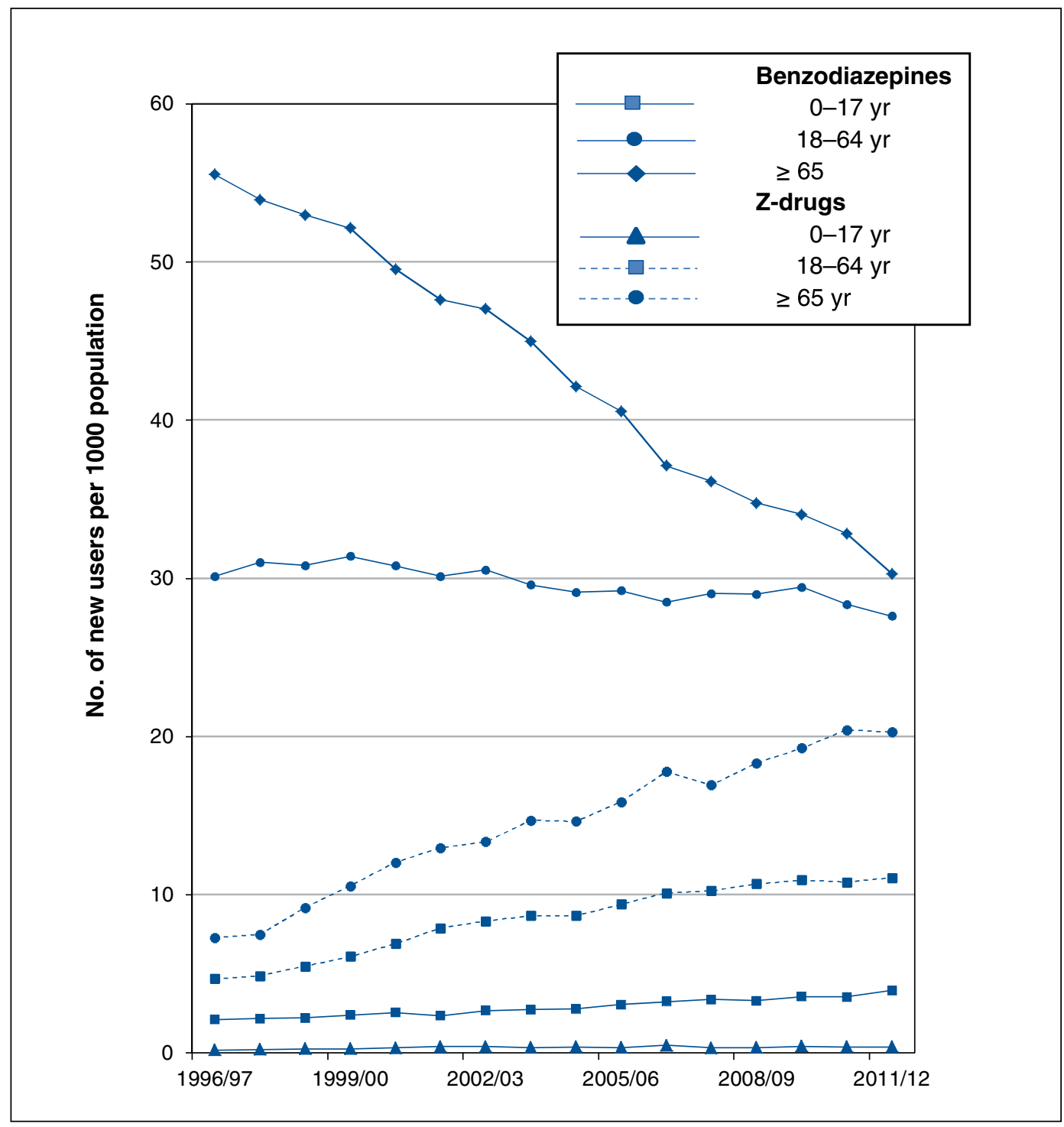

Figure 2: Incidence of benzodiazepine and Z-drug (zopiclone and zaleplon) use by age group in Manitoba, 1996-2012. 
total of 379259 prescriptions were for benzodiazepines alone and 44020 were for Z-drugs. By 2011/12, the number of prescriptions for benzodiazepines and Z-drugs had increased to 726409 and 277811, respectively. Lorazepam was the benzodiazepine most often prescribed; it accounted for more than a third of all benzodiazepine prescriptions. Each year, general practitioners wrote more than $80 \%$ of all prescriptions for these drugs and psychiatrists wrote approximately $15 \%$; the remainder were written by physicians of other medical specialties.

\section{Interpretation}

Substantial changes in prescription patterns were observed in Manitoba over the study period. Over time, fewer patients were started on a benzodiazepine, although the prevalence of use was not significantly affected but remained relatively stable in the adult population (18-64 yr). This suggests that patients were probably staying on medications longer than recommended.

Our analyses differentiated between benzodiazepines and the Z-drugs, zopiclone and zaleplon, which are not chemically related to benzodiazepines but share similar pharmacologic activity with respect to the $\gamma$-aminobutyric acid (GABA) type A receptor. Z-drugs have been marketed as hypnotic medications superior to benzodiazepines mainly because of their favourable pharmacokinetic and safety profiles despite the lack of evidence of substantial clinical advantages over appropriate doses of shorter-acting benzodiazepines. ${ }^{27}$

Other international studies have shown an increase in Z-drug use over time while benzodiazepine use decreased, especially among people over 65 years of age. ${ }^{28-31}$ In Canada, prescribing of benzodiazepines and Z-drugs in British Columbia decreased slightly from 1996 to 2006 in older people, but increased in younger segments of the population (females and people with low income). ${ }^{20}$ To set our results in the context of other reports and to assess use of these drugs in the oldest and youngest groups, we stratified our population into 3 age groups.

We observed sex differences in our study: both prevalence and incidence of benzodiazepine and Z-drug use were consistently higher among women, especially older women. Although this finding is not unique to the Canadian context, studies in other countries, where insurance coverage of short-

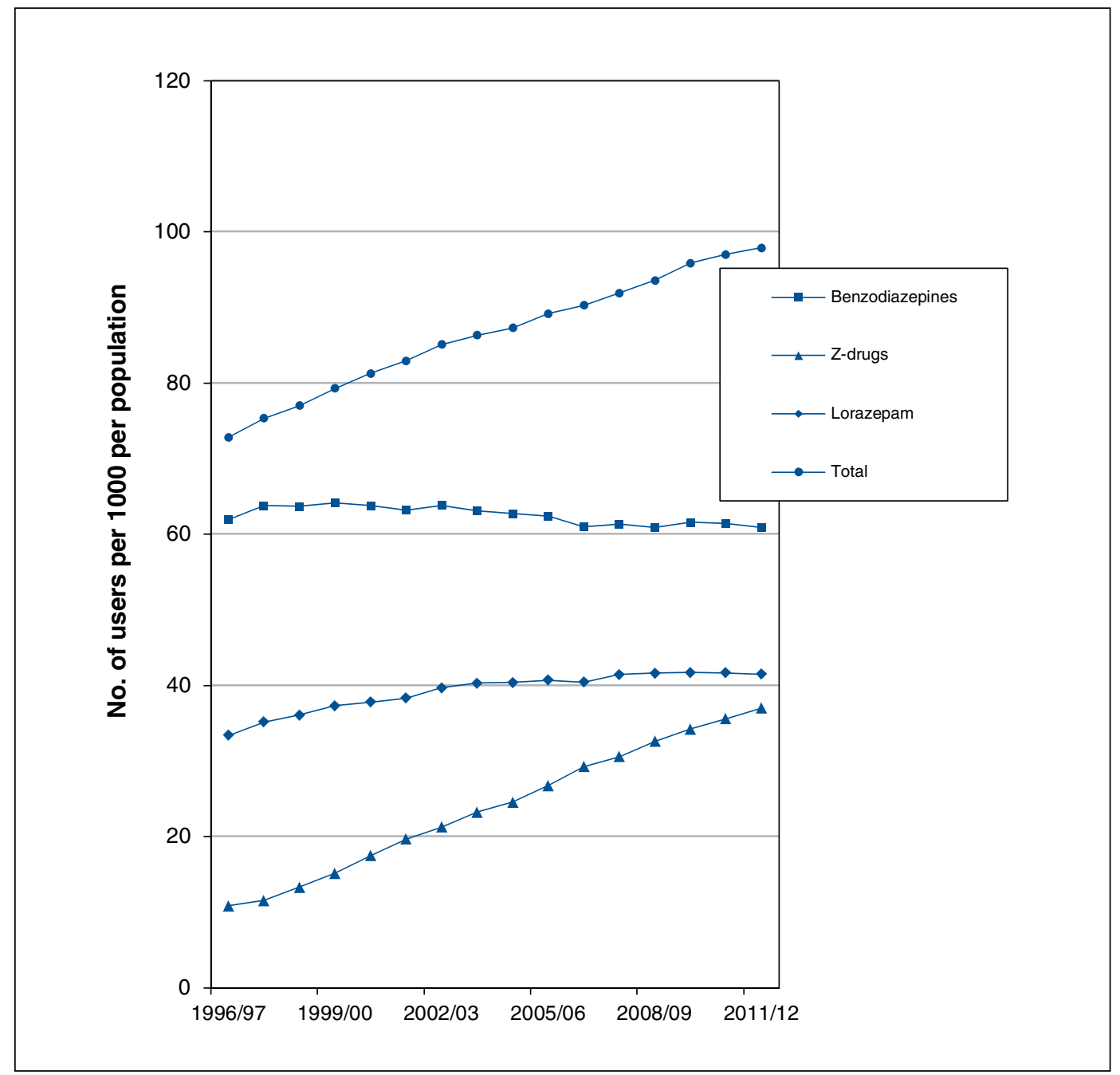

Figure 3: Prevalence of benzodiazepine and Z-drug (zopiclone and zaleplon) use in Manitoba, 1996-2012. 
acting benzodiazepines and $\mathrm{Z}$-drugs is restricted, have reported that male patients were more likely to receive benzodiazepines than female patients. ${ }^{30}$ Place of residence did not seem to have a substantial effect on incidence, but low income was associated with greater use of benzodiazepines than Z-drugs. The higher rates of mental disorders among women and lower socioeconomic status groups may explain this finding. ${ }^{32}$ Government-sponsored drug programs have covered these drugs as unrestricted benefits; therefore, no segment of the population could have experienced access limitations.

\section{Limitations}

Our study has some recognized limitations. Administrative data do not provide information on clinical benefits. Medication use in hospitals is not captured, although information on nonhospital use is comprehensive. The prescription database does not include information on diagnoses and comorbidities; however, Z-drugs are indicated specifically for the treatment of insomnia, and it has been suggested that some physicians still perceive that they are safer and more effective than benzodiazepines for this condition. ${ }^{33}$ Therefore, it could be inferred that insomnia might be the most prevalent diagnosis affected

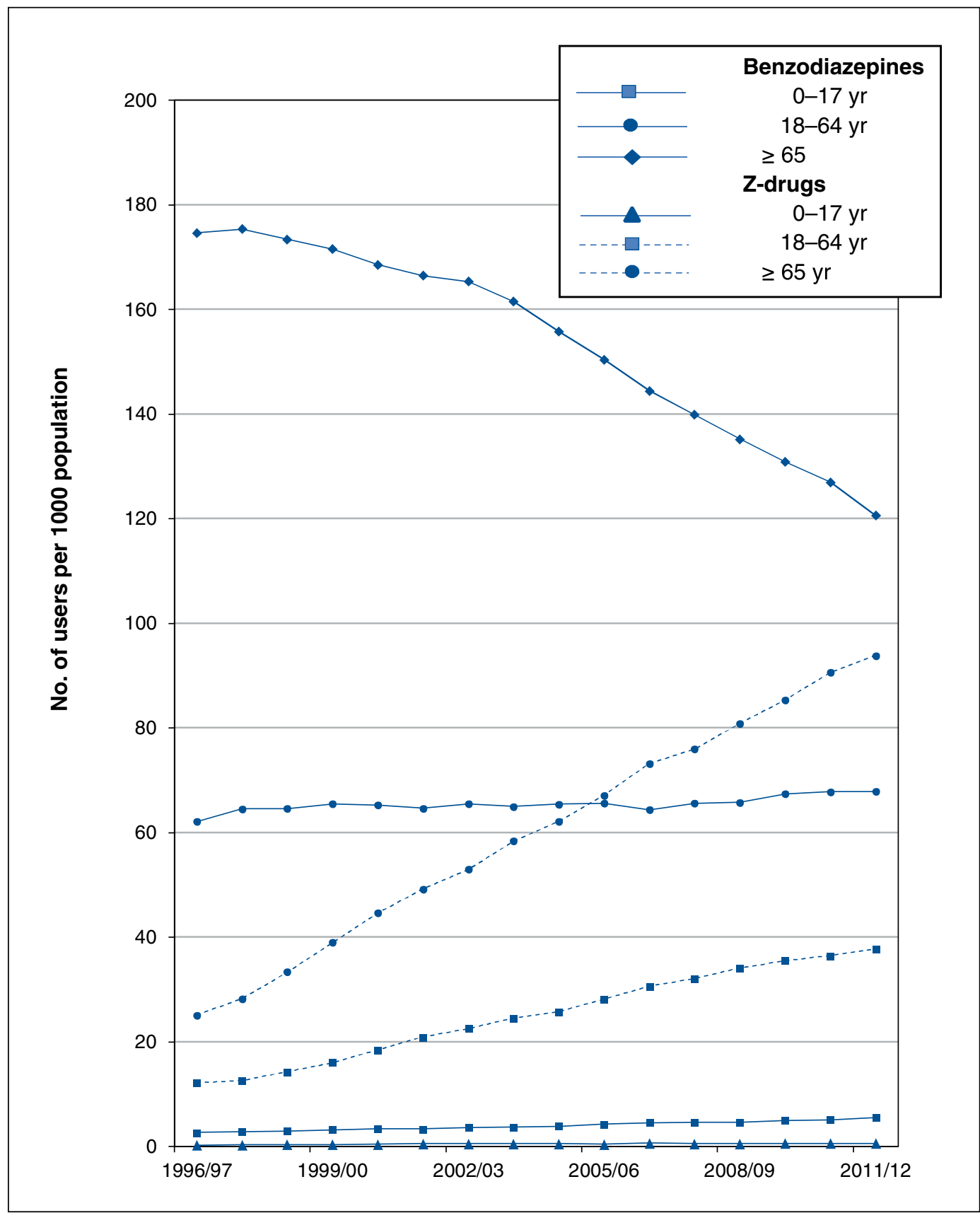

Figure 4: Prevalence of benzodiazepine and Z-drug (zopiclone and zaleplon) use by age group in Manitoba, 1996-2012. 
Table 1: Effects of age, sex, location of residence and socioeconomic status on the incidence of benzodiazepine and Z-drug (zopiclone and zaleplon) use in Manitoba, 1996-2012

\begin{tabular}{|c|c|c|c|}
\hline \multirow[b]{2}{*}{ Variable } & \multicolumn{3}{|c|}{ Drug use; relative rate* } \\
\hline & $\begin{array}{c}\text { Benzodiazepines } \\
\text { and Z-drugs } \\
\text { overall }\end{array}$ & $\begin{array}{l}\text { Benzodiazepines } \\
\text { alone }\end{array}$ & $\begin{array}{l}\text { Z-drugs } \\
\text { alone }\end{array}$ \\
\hline \multicolumn{4}{|l|}{$\begin{array}{l}\text { Users per } 1000 \\
\text { population }\end{array}$} \\
\hline $1996 / 97$ & 30.2 & 26.3 & 3.9 \\
\hline $2011 / 12$ & 32.4 & 22.5 & 9.9 \\
\hline Change in annual rate & 1.00 & $0.99 \dagger$ & $1.06 \dagger$ \\
\hline \multicolumn{4}{|l|}{ Age } \\
\hline $18-64 v . \geq 65$ & $0.65 \dagger$ & $0.70 \dagger$ & $0.56 \dagger$ \\
\hline $0-17$ v. $\geq 65$ & $0.06 \dagger$ & $0.07 \dagger$ & $0.02 \dagger$ \\
\hline Sex, male v. female & $0.70 \dagger$ & $0.69 \dagger$ & $0.72 \dagger$ \\
\hline Location, rural v. urban & 1.07 & 0.91 & 0.93 \\
\hline \multicolumn{4}{|l|}{ Socioeconomic status } \\
\hline High v. low & 0.97 & 0.93 & $1.10 \dagger$ \\
\hline Not found $\ddagger$ v. low & $1.21 \dagger$ & $1.32 \dagger$ & 0.85 \\
\hline \multicolumn{4}{|c|}{$\begin{array}{l}\text { *Unless states otherwise. Relative rates were adjusted for age, socioeconomic status, region and } \\
\text { sex. } \\
\text { †Significant effect }(p<0.05) \text {. } \\
\text { łlncludes people to whom a neighbourhood income could not be assigned, i.e., residents of } \\
\text { personal care homes, psychiatric facilities and prisons as well as wards of the public trustee and } \\
\text { Child and Family Services. }\end{array}$} \\
\hline
\end{tabular}

\begin{tabular}{|c|c|c|c|}
\hline \multirow[b]{2}{*}{ Variable } & \multicolumn{3}{|c|}{ Drug use; relative rate* } \\
\hline & $\begin{array}{l}\text { Benzodiazepines } \\
\text { and Z-drugs }\end{array}$ & $\begin{array}{l}\text { Benzodiazepines } \\
\text { alone }\end{array}$ & $\begin{array}{l}\text { Z-drugs } \\
\text { alone }\end{array}$ \\
\hline \multicolumn{4}{|l|}{$\begin{array}{l}\text { Users per } 1000 \\
\text { population }\end{array}$} \\
\hline $1996 / 97$ & 72.8 & 66.7 & 10.9 \\
\hline $2011 / 12$ & 97.9 & 72.4 & 37.0 \\
\hline Change in annual rate & $1.02 \dagger$ & 1.01 & $1.08 \dagger$ \\
\hline \multicolumn{4}{|l|}{ Age } \\
\hline $18-64$ v. $\geq 65$ & $0.50 \dagger$ & $0.52 \dagger$ & $0.44 \dagger$ \\
\hline $0-17$ v. $\geq 65$ & $0.03+$ & $0.03 \dagger$ & $0.01 \dagger$ \\
\hline Sex, male v. female & $0.66 \dagger$ & $0.65 \dagger$ & $0.64 \dagger$ \\
\hline Location, rural v. urban & $0.88 \dagger$ & $0.85 \dagger$ & 1.04 \\
\hline \multicolumn{4}{|l|}{ Socioeconomic status } \\
\hline High v. low & 0.91 & $0.88 \dagger$ & $1.02 \dagger$ \\
\hline Not found $\ddagger$ v. low & $1.53+$ & $1.56 \dagger$ & $1.25 \dagger$ \\
\hline \multicolumn{4}{|c|}{$\begin{array}{l}\text { *Unless states otherwise. Relative rates were adjusted for age, socioeconomic status, region and } \\
\text { sex. } \\
\text { †Significant effect }(p<0.05) \text {. } \\
\text { łIncludes people to whom a neighbourhood income could not be assigned, i.e., residents of } \\
\text { personal care homes, psychiatric facilities and prisons as well as wards of the public trustee and } \\
\text { Child and Family Services. }\end{array}$} \\
\hline
\end{tabular}


by a switch from a benzodiazepine to a Z-drug. It is important to note that zaleplon was discontinued in 2007 and that its use in Manitoba has been generally low: prevalence was below 1.0 per 1000 between 2001/02 and 2007/08, and incidence approached 0.1 per 1000 in 2005/06. Thus, zopiclone alone accounts for the rapid increase in the use of Z-drugs. As we collected no information on daily doses, duration of use or comedications, no conclusions on appropriateness of prescribing can be derived from this study. Finally, prescription databases are only records of dispensations and not of medication consumption.

Our study was not designed to assess the impact of specific warnings or interventions aimed at improving prescribing habits; however, it appears that physicians in Manitoba have been concerned about the potential harm of prescribing benzodiazepines to their older patients, as has been the case for other psychotropic medications, ${ }^{34}$ and have responded by starting fewer and fewer older people on a benzodiazepine. The rise in zopiclone prescribing, however, remains a reason for concern.

Patients of all ages seem to remain on a benzodiazepine or zopiclone for extended periods and might experience difficulties in discontinuing treatment. It is important to explore interventions ${ }^{35,36}$ that can help patients discontinue use of benzodiazepines and Z-drugs when they are no longer needed.

\section{Conclusion}

Although it appears that, over time, benzodiazepines have been prescribed less frequently to older patients in Manitoba, zopiclone prescribing has continued to rise among all age groups. It remains to be investigated whether the decline in benzodiazepine use is limited to the diagnosis of insomnia or whether other medications have replaced benzodiazepine for conditions such as anxiety.

\section{References}

1. Bateson AN. Basic pharmacologic mechanisms involved in benzodiazepine tolerance and withdrawal. Curr Pharm Des 2002;8:5-21.

2. Lader M. History of benzodiazepine dependence. 7 Subst Abuse Treat 1991;8:53-9.

3. Busto U, Lanctot KL, Isaac $\mathrm{P}$, et al. Benzodiazepine use and abuse in Canada. CMA7 1989;141:917-21.

4. Leipzig RM, Cumming RG, Tinetti ME. Drugs and falls in older people: a systematic review and meta-analysis: I. Psychotropic drugs. 7 Am Geriatr Soc 1999;47:30-9.

5. Bartlett G, Abrahamowicz M, Grad R, et al. Association between risk factors for injurious falls and new benzodiazepine prescribing in elderly persons. $B M C$ Fam Pract 2009;10:1.

6. Hill KD, Wee R. Psychotropic drug-induced falls in older people: a review of interventions aimed at reducing the problem. Drugs Aging 2012;29:15-30.

7. Chang CM, Chia-Husuan E, Chen CY, et al. Psychotropic drugs and risk of motor vehicle accidents: a population-based case-control study. Br 7 Clin Pharmacol 2013;75:1125-33.

8. Barker MJ, Greenwood KM, Jackson M, et al. Cognitive effects of long-term benzodiazepine use: a meta-analysis. CNS Drugs 2004;18:37-48.

9. Cimolai N. Zopiclone: is it a pharmacological agent for abuse? Can Fam Physician 2007;53:2124-9.

10. Orriols L, Philip P, Moore N, et al. Benzodiazepine-like hypnotics and the associated risk of road traffic accidents. Clin Pharmacol Ther 2011;89:595-601.

11. Gunja N. In the Zzz zone: the effects of $Z$-drugs on human performance and driving. 7 Med Toxicol 2013;9:163-71.

12. Donaldson L. Benzodiazepines warning. London (UK): Department of Health; 2004. Available: www.benzo.org.uk/cmo.htm (accessed 2013 Sept. 24).

13. Haslam B. Beat the benzos. A call for European Union guidelines on the prescribing of benzodiazepines, Europe's most harmful drugs. London (UK): Beat the Benzos Campaign; 2004. Available: www.benzo.org.uk/btb4.htm (accessed 2013 Sept. 24)
14. National Prescribing Centre. Benzodiazepines and newer hypnotics. $M e \operatorname{ReC}$ Bulletin 2005;15:17-20. Available: www.npc.nhs.uk/merec/cns/insomnia /resources/merec_bulletin_vol15_no5.pdf (accessed 2014 May 16).

15. Fick DM, Cooper JW, Wade WE, et al. Updating the Beers criteria for potentially inappropriate medication use in older adults: results of a US consensus panel of experts. Arch Intern Med 2003;163:2716-24.

16. McLeod PJ, Huang AR, Tamblyn RM, et al. Defining inappropriate practices in prescribing for elderly people: a national consensus panel. CMAf 1997; 156:385-91.

17. Beers MH. Explicit criteria for determining potentially inappropriate medication use by the elderly. An update. Arch Intern Med 1997;157:1531-6.

18. el-Guebaly N, Sareen J, Stein MB. Are there guidelines for the responsible prescription of benzodiazepines? Can $\mathcal{F}$ Psychiatry 2010;5 5:709-14.

19. Stephenson CP, Karanges E, McGregor IS. Trends in utilisation of psychotropic medications in Australia from 2000 to 2011. Aust N Z 7 Psychiatry 2013; 47:74-87.

20. Cunningham CM, Hanley GE, Morgan S. Patterns in the use of benzodiazepines in British Columbia: examining the impact of increasing research and guideline cautions against long-term use. Health Policy 2010;97:122-9.

21. Ilyas S, Moncrieff J. Trends in prescriptions and costs of drugs for mental disorders in England, 1998-2010. Br 7 Psychiatry 2012;200:393-8.

22. Gorevski E, Bian B, Kelton CM, et al. Utilization, spending, and price trends for benzodiazepines in the US Medicaid program: 1991-2009. Ann Pharmacother 2012;46:503-12.

23. Concept dictionary and glossary for health services research. Winnipeg: Manitoba Centre for Health Policy; 2012. Available: www.umanitoba.ca/faculties/medicine /units/community_health_sciences/departmental_units/mchp/resources/concept dictionary.html (accessed 2013 Oct. 7)

24. Kozyrskyj AL, Mustard CA. Validation of an electronic, population-based prescription database. Ann Pharmacother 1998;32:1152-7.

25. Liang KY, Zeger SL. Longitudinal data analysis using generalized linear models. Biometrika 1986;73:13-22.

26. Zeger SL, Liang KY, Albert PS. Models for longitudinal data: a generalized estimating equation approach. Biometrics 1988;44:1049-60.

27. Guidance on the use of zaleplon, zolpidem and zopiclone for the short-term management of insomnia. London (UK): National Institute for Clinical Excellence; 2007. Available: www.nice.org.uk/nicemedia/live/11530/32845/32845.pdf (accessed 2014 June 12)

28. Clay E, Falissard B, Moore T, et al. Contribution of prolonged-release melatonin and anti-benzodiazepine campaigns to the reduction of benzodiazepine and Z-drugs consumption in nine European countries. Eur 7 Clin Pharmacol 2013;69:1-10.

29. Neutel CI, Skurtveit S, Berg C. What is the point of guidelines? Benzodiazepine and z-hypnotic use by an elderly population. Sleep Med 2012;13:893-7.

30. Johnell K, Fastbom J. Gender and use of hypnotics or sedatives in old age: a nationwide register-based study. Int 7 Clin Pharm 2011;33:788-93.

31. Hausken AM, Furu K, Skurtveit S, et al. Starting insomnia treatment: the use of benzodiazepines versus z-hypnotics. A prescription database study of predictors. Eur 7 Clin Pharmacol 2009;65:295-301.

32. Sareen J, Afifi TO, McMillan KA, et al. Relationship between household income and mental disorders: findings from a population-based longitudinal study. Arch Gen Psychiatry 2011;68:419-27.

33. Hoffmann F. Perceptions of German GPs on benefits and risks of benzodiazepines and Z-drugs. Swiss Med Wkly 2013;143:w13745.

34. Alessi-Severini S, Dahl M, Schultz J, et al. Prescribing of psychotropic medications to the elderly population of a Canadian province: a retrospective study using administrative databases. Peer7 2013;1:e168.

35. Gorgels WJ, Oude Voshaar RC, Mol AJ, et al. Discontinuation of long-term benzodiazepine use by sending a letter to users in family practice: a prospective controlled intervention study. Drug Alcohol Depend 2005;78:49-56.

36. Martin P, Tamblyn R, Ahmed S, et al. A drug education tool developed for older adults changes knowledge, beliefs and risk perceptions about inappropriate benzodiazepine prescriptions in the elderly. Patient Educ Couns 2013; 92:81-7.

Affiliations: Faculty of Pharmacy (Alessi-Severini, Collins), Department of Psychiatry (Bolton, Enns, Sareen), Department of Community Health Sciences (Bolton, Enns, Chateau, Sareen), Faculty of Medicine, Department of Psychology (Enns, Bolton, Sareen), Faculty of Arts, Manitoba Centre for Health Policy (Dahl, Chateau), University of Manitoba, Winnipeg, Man.

Contributors: Silvia Alessi-Severini and James Bolton contributed equally to this project. All authors contributed to the design and interpretation of the study. Silvia Alessi-Severini wrote the paper, Matthew Dahl conducted the analyses. All authors contributed to the writing and approved the final version. All of the authors agree to act as guarantors for this work.

Funding: Preparation of this article was supported by an operating grant from the Health Sciences Centre Foundation (James Bolton and Silvia Alessi-Severini). Additional investigator support includes the following 
salary awards: a Manitoba Health Research Council Establishment Award (James Bolton), a Manitoba Health Research Council Chair Award (Jitender Sareen) and a Canadian Institutes of Health Research New Investigator Award (\#152348, Jitender Sareen).

Acknowledgements: The authors acknowledge the Manitoba Centre for Health Policy, University of Manitoba, for use of data contained in the Population Health Research Data Repository under project \#2009-020, and derived from data provided by Manitoba Health. The results and conclusions are those of the authors and no official endorsement by Manitoba Health, the Manitoba Centre for Health Policy or other data providers is intended or should be inferred.

Supplemental information: For reviewer comments and the original submission of this manuscript, please see www.cmajopen.ca/content/2/4 /E208/suppl/DC1 